\title{
Los orígenes de la conducta soviética*
}

George F. Kennan

Con el seudónimo de " $x$ ", George F. Kennan publicó en la prestigiosa revista Foreign Affairs, en julio de 1947, un artículo titulado "Los origenes de la conducta soviética" que, junto con la Doctrina Truman, se convertiria en el manifiesto de la guerra fria.

Kennan, quien habia sido Encargado de Negocios de los Esiados Unidos en Moscú y era a la sazón el responsable del equipo de planificación política del Departamento de Estado, planteaba una política de "contención" para hacer frente a la Unión Soviética en el lugar y en el tiempo en que diese signos de entrometerse en "los intereses de un mundo pacifico y estable", para frentar sus inclinaciones expansionistas y eventualmente disuadirla.

El desafío descrito por el diplomático era de índole política y económica, y la actitud que proponía, de vigilancia. Sin embargo, al decir que se requería "la diestra y hábil aplicación de fuerzas de contención en una serie de puntos geográficos y políticos en constante variación, de acuerdo con los cambios y maniobras de la politica soviética", hizo suponer a muchos que la amenaza era militar, y que las crisis mundiales serian permanentes, pues los agentes del comunismo ruso llegaban a todos los "rincones" y a todas las "grietas" del orbe.

De esta suerte, "Los orígenes de la conducta soviética" propiciaría el desarrollo militar de los Estados Unidos y de sus aliados, que de otra forma no podrian encarar a los rusos cuando y donde presionaran, y alimentó la paranoia anticomunista de aquella nación.

a personalidad política del poder soviético tal como la conocemos ahora es producto de ideología y circunstancias: ideología que los actuales líderes soviéticos heredaron del movimiento en el cual tuvieron su origen político, y circunstancias del poder que han ejercido ya durante casi tres décadas en Rusia. Pocas tareas de análisis psicológico resultan tan difíciles como tratar de rastrear la interacción de estas dos fuerzas y el papel relativo de cada una en la determinación de la conducta oficial soviética. Sin embargo, debe hacerse el esfuerzo si se pretende entender y enfrentar debidamente tal conducta.

Es difícil resumir el conjunto de conceptos ideológicos con los que los líderes soviéticos llegaron al poder. La ideologia marxista, en su proyección rusocomunista, ha estado siempre en un sutil proceso de evolución. Los materiales en los cuales se basa son extensos y complejos. Pero las caracteristicas sobresalientes del pensamiento comunista tal como existía en 1916 quizás pueden resumirse de la manera siguiente: a) que el factor central en la vida del hombre, el factor que determina el carácter de la vida pública y la "fisonomía de la sociedad", es el sistema por el cual se producen e intercambian los bienes materiales; b) que el sistema capitalista de producción es infame y conduce inevitablemente a la explotación de la clase trabajadora por la clase propietaria del capital y es incapaz de desarrollar de forma adecuada los recursos económicos de la sociedad o de distribuir con justicia los bienes materiales producidos por el trabajo del hombre; c) que el

* Publicado originalmente en inglés bajo el título de "The Sources of Soviet Conduct". en Foreign Affairs, julio de 1947, vol. 25. p. 566-582, traducción de Eva Salgado Andrade. 
capitalismo contiene las semillas de su propia destrucción y, en vista de la incapacidad de la clase propietaria del capital para ajustarse al cambio económico, con el tiempo y de forma irremisible se da lugar a una transferencia revolucionaria del poder a la clase trabajadora, y d) que el imperialismo, fase final del capitalismo, conduce directamente a la guerra y la revolución.

El resto puede esbozarse con las propias palabras de Lenin:

La desigualdad del desarrollo económico y político es la ley inflexible del capitalismo. De aquí se deduce que la victoria del socialismo puede darse originalmente en unos cuantos paises capitalistas o inclusive en un solo país capitalista. El proletariado victorioso de ese país, después de expropiar a los capitalistas y reorganizar la producción socialista nacional, se levantaría en contra del resto del mundo capitalista y, durante este proceso, atraería hacia sí a las clases oprimidas de otros países. ${ }^{1}$

Debe hacerse notar que no se asumía que el capitalismo podría perecer sin revolución proletaria. Se necesitaba el impulso final de un movimiento proletario revolucionario a fin de derrumbar la tambaleante estructura. Pero se veía como algo inevitable que ese impulso se diese tarde o temprano.

Desde unos cincuenta años antes de estallar la Revolución, este modelo de pensamiento habia ejercido gran fascinación en los miembros del movimiento revolucionario en Rusia. Frustrados, inconformes, sin esperanzas de encontrar su propia personalidad -o demasiado impacientes para buscarla - en los restringidos límites del sistema político zarista, aunque sin recibir un amplio apoyo popular al elegir una revolución sangrienta como medio de mejoramiento social, estos revolucionarios vieron en la teoría marxista una racionalización altamente conveniente para sus propios deseos instintivos. Proporcionaba la justificación seudocientífica a su impaciencia, a su categórica negación de la validez del sistema zarista, a su ambición de poder y venganza y a su inclinación por ahorrarse esfuerzos en esta búsqueda. Por lo tanto no es de extrañar que hayan creido tácitamente en la verdad y firmeza de las enseñanzas marxistas-leninistas, que convenían tambien a sus propios impulsos y emociones. Su sinceridad no necesita ser impugnada. Este es un fenómeno tan viejo como la naturaleza humana. Nadie lo ha descrito más atinadamente que Edward Gibbon quien, en La decadencia y la caida del Imperio Romano, escribió:

El paso que lleva del entusiasmo a la impostura es peligroso y resbaloso; el demonio de Sócrates ofrece un memorable ejemplo de cómo un hombre sabio puede engañarse a sí mismo, cómo un hombre bueno puede engañar a otros, cómo la conciencia puede tornarse inactiva y oscilar entre la autoilusión y el fraude voluntario.

Con este juego de concepciones, los miembros del Partido Bolchevique llegaron al poder.

" "Concerning the Slogans of the United States of Europe", agosto de 1915, edición oficial soviética de los trabajos de Lenin. 
Debe notarse ahora que a lo largo de todos los años en que se preparaban para la revolución, la atención de estos hombres, al igual que la del propio Marx, se había centrado menos en la forma futura que adoptaría el socialismo ${ }^{2}$ que en el necesario derrocamiento del poder rival, lo cual, en su opinión, debía preceder a la introducción del socialismo. Por lo tanto, sus puntos de vista con respecto al programa efectivo que entraría en vigor una vez que obtuvieran el poder eran nebulosos, visionarios e impracticables en su mayoría. Más allá de la nacionalización de la industria y la expropiación de grandes empresas capitalistas privadas, no se había acordado programa alguno. El tratamiento del campesinado, que de acuerdo con la formulación marxista no pertenecía al proletariado, había sido siempre una mancha vaga en el modelo del pensamiento comunista; y permanecería como un objeto de controversia y vacilaciones durante los primeros diez años del poder comunista.

Las circunstancias del periodo posrevolucionario inmediato -existencia en Rusia de una guerra civil e intervención extranjera, junto con el hecho obvio de que los comunistas representaban sólo una reducida minoría del pueblo ruso- hicieron necesario establecer un poder dictatorial. El experimento con el "comunismo de guerra" y el abrupto intento de eliminar la producción y el comercio privados tuvieron desafortunadas consecuencias económicas y aumentaron la amargura en contra del nuevo régimen revolucionario. Si bien el relajamiento temporal del esfuerzo para comunizar a Rusia - representado por la Nueva Política Económica - mitigaba un poco este desastre económico y por lo tanto cumplía sus propósitos, también hizo evidente que el "sector capitalista de la sociedad" estaba todavía preparado para sacar inmediato provecho a cualquier distensión de las presiones gubernamentales $\mathrm{y}$, si se le permitía seguir existiendo, constituiría siempre un poderoso elemento de oposición al régimen soviético y un serio rival para su influencia en el país. De alguna manera la misma situación prevalecía con respecto a los campesinos en tanto que individuos que, aunque en pequeña escala, eran también productores privados.

En caso de haber vivido, Lenin habría demostrado ser un hombre capaz de reconciliar estas fuerzas conflictivas para beneficiar en última instancia a la sociedad rusa, aunque esto es cuestionable. Pero si así hubiera sido, Stalin, y aquellos a los cuales él condujo en la lucha para suceder en el liderazgo a Lenin, no podrían tolerar fuerzas políticas rivales en la esfera de poder codiciada por ellos. Su sentido de inseguridad era demasiado grande. Su peculiar fanatismo -que no había sido modificado por ninguna de las tradiciones anglosajonas de compromiso- era demasiado feroz y envidioso como para permitirles vislumbrar que compartirian permanentemente el poder. El mundo rusoasiático del cual emergían, dos había tornado escépticos en lo referente a las posibilidades de coexistir permanente y pacificamente con fuerzas rivales. Con facilidad se persuadieron de su propia "rectitud" doctrinaria e insistieron en la sumisión o destrucción de todos los poderes que les hicieran competencia. En la sociedad rusa no habría más rigor que el del Partido Comunista. No habría actividades huma-

"Aquí y a lo largo de todo este trabajo, "socialismo" se refiere al comunismo marxista o leninista, no al socialismo liberal que es una variedad de la Segunda Internacional. 
nas colectivas o asociaciones que no estuvieran dominadas por el Partido. A ninguna otra fuerza en la sociedad rusa se le podría asegurar vitalidad o integridad. Sólo el Partido tendría estructura. Todo lo demás sería sólo una masa amorfa.

Y dentro del Partido se aplicaría el mismo principio. Todos sus miembros podrian participar en las mociones de elección, deliberación, decisión y acción; pero en estos procedimientos estarían animados no por sus propios deseos individuales, sino por el impresionante aliento de los líderes del Partido y la avasallante presencia de "la palabra".

Hay que recalcar que subjetivamente estos hombres tal vez no buscaban el absolutismo por su propia cuenta. Sin duda creían - y les resultaba fácil creer - que por sí solos sabian qué era benéfico para la sociedad y que ellos conseguirian esos beneficios una vez que su poder fuera seguro e inalterable. Pero al tratar de asegurar su propio dominio, no estaban dispuestos a permitir restricción alguna a sus métodos, ya fuera por parte de Dios o de los hombres. Y hasta que se hubiera obtenido tal seguridad, quedaba muy lejos en su escala de prioridades la tranquilidad y la felicidad de los pueblos cuyo cuidado se les había confiado.

Una circunstancia sobresaliente en relación con el régimen soviético actual es que hasta la fecha no se ha completado este proceso de consolidación política, y los hombres del Kremlin siguen consagrados predominantemente a la lucha por asegurar y hacer absoluto el poder que tomaron en noviembre de 1917. Antes que nada, se han esforzado por asegurarlo en contra de las fuerzas locales, en el propio ámbito de la sociedad soviética. Pero también se han esforzado por asegurarlo en contra del mundo exterior. Porque la ideología, como hemos visto, les enseñó que el mundo exterior era hostil y que con el tiempo su deber sería derrocar a las fuerzas políticas más allá de sus fronteras. Las poderosas manos de la historia y la tradición rusas se alzaron para apoyarlos en este sentimiento. Finalmente, su propia intransigencia agresiva respecto al mundo exterior empezó a encontrar su propia reacción; y se vieron obligados, para usar otra frase gibbonesca, "a castigar la contumàcia" que ellos mismos habian provocado. Todo hombre tiene el privilegio inalienable de probar que tiene razón en la tesis de que el mundo es su enemigo; puesto que si reitera este argumento con la suficiente frecuencia y lo convierte en la guía de su conducta, con el tiempo estará destinado a tener la razón.

Ahora bien, de acuerdo con la naturaleza del mundo mental de los líderes soviéticos, así como del carácter de su ideología, no se reconocerá cualquier mérito o justificación a ninguna oposición. En teoria, tal oposición sólo puede surgir de las fuerzas hostiles e incorregibles del capitalismo agonizante. Mientras se reconoció oficialmente la presencia de remanentes del-capitalismo en Rusia, fue posible responsabilizar a éstos, como un elemento interno, de la preservación de una sociedad dictatorial. Pero a medida que los remanentes fueron poco a poco liquidados, esta justificación comenzó a perder peso; y cuando oficialmente se indicó que habían sido destruidos, la justificación desapareció junto con ellos. Este hecho dio lugar a una de las compulsiones fundamentales que actuaron sobre el régimen soviético: en vista de que el capitalismo ya no existía en Rusia y dado que no podía admitirse una seria o extensa oposición al Kremlin surgida espontáneamente de las masas liberadas a las cuales gobernaban, se tuvo que 
reforzar la amenaza del capitalismo más allá de las fronteras, para justificar la persistencia de la dictadura.

Esto empezó desde muy pronto. En 1924, Stalin defendió especificamente la preservación de los "órganos represivos", que se referían, entre otros, al ejército y a la policía secreta, con el argumento de que "siempre que haya un cerco capitalista habrá peligro de intervención con todas las consecuencias que surgen de ese peligro". De acuerdo con esta teoria, y a partir de entonces, las fuerzas internas de oposición en Rusia han sido constantemente consideradas como agentes de las fuerzas extranjeras reaccionarias antagonistas al poder soviético.

Por la misma razón, se ha dado tremendo énfasis a la tesis original del antagonismo básico entre los mundos capitalista y socialista. Según varias indicaciones, es claro que este énfasis no se basa en la realidad. Los hechos que verdaderamente se relacionan con él se han tornado confusos por la presencia exterior de resentimientos genuinos provocados por la filosofia y tácticas soviéticas, y ocasionalmente por la existencia de grandes centros de poder militar, que sin duda tenían metas agresivas contra la Unión Soviética, especialmente el régimen nazi en Alemania y el gobierno japonés de finales de la década de 1930. Pero hay amplias evidencias de que el énfasis desplegado por Moscú con respecto a la amenaza que se cierne sobre la sociedad soviética, y que provenía del mundo más allá de sus fronteras, en realidad no se funda en antagonismos externos, sino en la necesidad de explicar el mantenimiento de una autoridad dictatorial en la nación.

En la actualidad, el mantenimiento de este modelo de poder soviético, concretamente la búsqueda de autoridad ilimitada en sus confines, junto con el semito de la implacable hostilidad extranjera, ha ido tan lejos que ha moldeado la maquinaria del poder soviético tal como la conocemos ahora. Los órganos internos de administración que no sirvieron para este propósito se debilitaron. Los órganos que sí sirvieron para este propósito crecieron exorbitantemente. La seguridad del poder soviético descansó en la disciplina de hierro del Partido, en la severidad y ubicuidad de la policía secreta, y en el inflexible monopolio económico del Estado. Los "órganos represivos", con los cuales los líderes soviéticos habían buscado protegerse de las fuerzas rivales, se volvieron en gran medida los amos de aquellos a los cuales se suponía debían servir. Actualmente la mayor parte de la estructura del poder soviético está encaminada a perfeccionar la dictadura y a mantener la imagen de Rusia como en estado de sitio, con el enemigo acechando tras las paredes. Y los millones de seres humanos que forman parte de la estructura de poder deben defender a cualquier costa este concepto de la posición rusa, pues en su ausencia ellos mismos se vuelven superfluos.

Como están las cosas, los dirigentes no pueden soñar siquiera en deshacerse de estos órganos represivos. La búsqueda del poder absoluto, perseguida desde hace ya casi tres décadas con una crueldad sin paralelos (al menos por su alcance) en los últimos tiempos, ha producido de nuevo internamente, como lo hizo externamente, su propia reacción. Los excesos del aparato policiaco han convertido la oposición potencial al régimen en algo aún mayor y más peligroso de lo que pudo haber sido antes de que comenzaran los excesos. 
Esto es lo que concierne a los antecedentes históricos. ¿Qué significa en términos de la personalidad política soviética tal como la conocemos ahora?

Nada ha sido oficialmente desechado de la ideología original. Persiste la creencia en la maldad básica del capitalismo, en su inevitable destrucción, en la obligación del proletariado de participar en tal destrucción y tomar el poder en sus propias manos. Pero se ha dado especial énfasis a aquellos conceptos más específicamente relacionados con el propio régimen soviético: con su posición como el único régimen verdaderamente socialista, en un mundo confuso y desorientado, y con las relaciones de poder involucradas en él.

El primero de estos conceptos es el de un antagonismo innato entre el capitalismo y el socialismo. Hemos visto la forma tan intensa en que este concepto ha penetrado en los cimientos del poder soviético. Son profundas sus implicaciones para la conducta de Rusia como miembro de una sociedad internacional. Significa que Moscú no puede concebir como sincero ningún esfuerzo en favor de intereses comunes entre la Unión Soviética y los poderes considerados como capitalistas. Invariablemente, en Moscú debs supc :erse que las metas del mundo capitalista se oponen a las del régimen soviético, y por lo tanto a los intereses de los pueblos bajo su contro:. Si ocasionalmente el gobierno soviético estampa su firma en documentos que indicasen lo contrario, deberá considerarse como una maniobra táctica permisible para tratar con el enemigo (el cual carece de honor) y debería ser considerado como un falso aviso. Básicamente, el antagonismo persiste. Está postulado. Y de él surgen muchos de los fenómenos que identificamos como obstáculos en la conducta del Kremlin en cuanto a la política extranjera: el sigilo, la falta de franqueza, la duplicidad, las sospechas cautelosas, y la oposición básica a sus propósitos. Estos fenómenos están alli para quedarse, para un futuro predecible. Puede haber variaciones en el orado o en el énfasis. Cuando los rusos quieran algo de nosotros, una u otra de estas características de su política puede dejarse temporalmente atrás; y cuando eso suceda siempre habrá norteamericanos que brincarán alegres y anunciarán gozosos que "los rusos han cambiado", y algunos inclusive pretenderán concederse el crédito por haber producido tales "cambios". Pero no debemos confundirnos por maniobras tácticas. Estas características de la política soviética, como el postulado del cual emanan, son parte esencial de la naturaleza interna del poder soviético, y estarán con nosotros, ya sea en primero o en segundo plano, hasta que cambie la naturaleza interna del poder soviético.

Esto significa que durante mucho tiempo nos resultará dificil tratar con los rusos. Esto no significa que debamos considerar que se han embarcado en un programa de "vencer o morir" para derrocar a nuestra sociedad en determinada fecha. La teoría de la inevitable caída del capitalismo tiene la afortunada connotación de que no lleva prisa alguna. Las fuerzas del progreso pueden tomarse su tiempo para asestar el coup de grace final. Mientras tanto, es vital que la "patria del socialismo" - ese oasis de poder que ha sido ya ganado para el socialismo en la Unión Soviética en sí- sea alabada y defendida por todos los buenos comunistas en casa y fuera de ella, su fortuna debería ser promovida y sus enemigos acosados y confundidos. Sería imperdo- 
nable e inclusive contrarrevolucionario promover proyectos revolucionarios prematuros y "aventureros" que de alguna manera pudieran poner en apuros al poder soviético. La razón del socialismo es el apoyo y la promoción del poder soviético, tal como se define en Moscú.

Esto nos lleva al segundo de los conceptos importantes en el panorama soviético contemporáneo. Se trata de la infalibilidad del! Kremlin. El concepto soviético del poder, que no permite puntos focales de organización fuera del propio Partido, requiere que el liderazgo de éste permanezca en teoría como el único depositario de la verdad. Puesto que si la verdad pudiera encontrarse en otra parte, habría justificación para que se expresara mediante una actividad organizada. Pero esto es precisamente lo que el Kremlin no permite y no permitirá.

Por lo tanto, el liderazgo del Partido Comunista siempre tendrá razón, y siempre la ha tenido desde que en 1929 Stalin formalizó su poder personal al anunciar que las decisiones del Politburó se tomaban unánimemente.

En el principio de la infalibilidad descansa la disciplina de hierro del Partido Comunista. De hecho, estos dos conceptos se apoyan uno al otro. La perfecta disciplina requiere aceptar la infalibilidad. La infalibilidad requiere la observancia de disciplina. Y las dos juntas determinan el comportamiento de todo el aparato del poder soviético. Pero su efecto no puede entenderse a menos que se tome en consideración un tercer factor: concretamente, el hecho de que los líderes tienen la libertad de sostener, con fines tácticos, cualquier tesis particular que sea útil a la causa en cualquier momento particular y requerir a los miembros del movimiento en conjunto la leal e incondicional aceptación de dicha tesis. Esto significa que la verdad no es constante, sino que es creada, para todas las metas y propósitos, por los propios líderes soviéticos. Puede variar de semana a semana, de mes a mes. No es absoluta e inmutable - no fluye de la realidad objetiva. Es sólo la más reciente manifestación de sabiduría de aquellos en los cuales se supone reside la máxima sabiduría, porque ellos representan la lógica de la historia. Como efecto acumulativo de estos factores todo el aparato subordinado al poder soviético adquiere una obstinación inquebrantable y una orientación tenaz. Esta orientación puede ser cambiada a voluntad por el Kremlin, y por ningún otro poder. Una vez que se establece una línea política relativa a determinado aspecto de la política actual, toda la maquinaria gubernamental soviética, incluyendo el mecanismo diplomático, se mueve inexorablemente a lo largo de la ruta prescrita, como un persistente automóvil de cuerda encaminado en una dirección establecida, que se detiene sólo cuando se encuentra con una fuerza a la que no puede combatir. Los individuos que integran esta máquina no tienen acceso a los argumentos o razones que provienen de fuentes externas. Todo su entrenamiento les ha enseñado a desconfiar y dejar de lado la verbosa persuasión del mundo exterior. Como el perro blanco delante del fonógrafo, ellos no escuchan mas que la "voz del amo". Y si se les pide que se retiren del propósito que se les acaba de dictar, es el amo quien debe pedirles tal retirada. Por lo tanto un representante extranjero no puede esperar que sus palabras hagan mella alguna en ellos. A lo más que puede aspirar es a que sean transmitidas a los que están en la cúspide, capaces de cambiar la línea del Partido. Pero inclusive éstos difícilmente pueden ser influidos por la lógica normal contenida en las palabras de los representantes de la burguesía. Dado que no se puede apelar a propósitos comunes, no se puede apelar a enfoques mentales 
comunes. Por esta razón, los hechos resuenan más alto que las palabras en los oídos del Kremlin; y las palabras pueden pesar más cuando reflejan o están apoyadas por hechos de validez irrebatible.

Pero hemos visto que el Kremlin no tiene compulsión ideológica para cumplir con rapidez sus metas. Como la Iglesia, está tratando con conceptos ideológicos cuya validez es de larga duración, y puede darse el lujo de ser paciente. No tiene derecho a arriesgar los logros de la revolución sólo por los triviales objetivos del futuro. Las enseñanzas del propio Lenin requieren gran cautela y flexibilidad para conseguir los propósitos comunistas. De nuevo, estos preceptos se fortalecen por las lecciones de la historia rusa: cientos de oscuras. batallas entre las fuerzas nómadas sobre vastas planicies sin fortificar. En ellas, la precaución, la circunspección, la flexibilidad y el engaño eran cualidades valiosas; y su valor es naturalmente apreciado en la mente rusa u oriental. Así, el Kremlin no siente remordimientos al emprender la retirada si se enfrenta a una fuerza superior. $Y$ al no estar obligado por horario alguno, no siente pánico frente a la necesidad de tal retirada. Su acción política es un arroyo fluido que se mueve constantemente, hacia donde se le permita moverse hasta llegar a una meta determinada. Su interés principal es asegurarse de haber llenado hasta el último rincón y la última grieta de la cuenca del poder mundial. Pero si en su camino encuentra metas invencibles, las acepta con filosofia y se adapta a ellas. Lo principal es que siempre debe haber presión, presión constante y sin descanso, hacia la meta deseada. En la psicología soviética no hay indicios de pretender que tal meta deba lograrse en un periodo determinado.

Estas consideraciones hacen que la diplomacia soviética sea a la vez más fácil y más difícil de entender que la diplomacia de agresivos líderes individuales, como Napoleón y Hitler. Por una parte es más sensible a las fuerzas contrarias, está más dispuesta a escudarse en sectores individuales del frente diplomático cuando estas fuerzas son demasiado poderosas, y por lo tanto es más racional en la lógica y la retórica del poder. Por otra parte, puede ser fácilmente derrotada o desanimada por una simple victoria de sus oponentes. Y la paciente persistencia que la anima significa que no puede enfrentarse efectivamente con actos esporádicos que representen los caprichos momentáneos de las opiniones democráticas, sino sólo por políticas inteligentes de largo alcance por parte de los adversarios de Rusia, políticas no menos firmes en su propósito, y no menos diversificadas y llenas de recursos en su aplicación, que las de la propia Unión Soviética.

En estas circunstancias es claro que el elemento central de cualquier política de los Estados Unidos hacia la Unión Soviética debe ser a largo plazo, una paciente pero firme y vigilante contención de las tendencias expansivas rusas. Es importante notar, sin embargo, que tal política no tiene nada que ver con histrionismos exteriores; con amenazas, jactancias o gestos superfluos de "rudeza" exterior. Mientras que el Kremlin es en esencia flexible en sus reacciones frente a las realidades políticas, no puede dejar de ser sensible a las consideraciones de prestigio. Como casi cualquier otro gobierno, las acciones carentes de tacto o los ademanes retadores lo pueden colocar en desventaja, aunque hubiera actuado de acuerdo con su sentido de la realidad. Los líderes rusos son agudos jueces de la psicología humana, y como tales están altamente conscientes de que la pérdida de la templanza y del autocontrol no es jamás una fuente de fuerza en asuntos 
políticos. Ellos se apresuran a explotar tales evidencias de debilidad. Por estas razones, para tener tratos exitosos con Rusia es un requisito sine qua non que el gobierno extranjero en cuestión permanezca siempre frío y reservado y que las demandas sobre la politica rusa sean expuestas de tal modo que se abra el camino para condescender sin demasiados perjuicios para el prestigio ruso.

\section{III}

A la luz de lo anterior, es claro que la presión soviética en contra de las instituciones libres del mundo occidental puede ser contenida mediante la diestra y hábil aplicación de fuerzas de contención en una serie de puntos geográficos y políticos en constante variación, de acuerdo con los cambios y maniobras de la política soviética, los cuales no podemos desaparecer como por encanto o hablar de ellos como si no existieran. Los rusos buscan un duelo de infinita duración, y según ellos ya han logrado gran éxito. Debe tenerse en mente que en alguna ocasión el Partido Comunista representaba sólo a una minoria en la esfera de la vida nacional rusa, apenas mayor a aquella que el poder soviético actual representa en la comunidad mundial.

Pero si la ideología convence a los dirigentes de Rusia de que la verdad está de su lado y que por lo tanto pueden darse el lujo de esperar, quienes no estamos sujetos a tal ideología somos libres para examinar objetivamente la validez de esa premisa. Según la tesis soviética, el occidente carece de control sobre su propio destino económico, en tanto que la unidad, la disciplina y la pacienciá rusas persistirán durante un periodo infinito. Traigamos esta visión apocalíptica a la tierra y supongamos que el mundo occidental encuentra la fuerza y los recursos para contener el poder soviético durante un periodo de diez a quince años. ¿Qué significa eso para la propia Rusia?

Los líderes soviéticos, sacando ventaja de los aportes de la técnica moderna al arte del despotismo, han resuelto el asunto de la obediencia dentro de los confines de su poder. Muy pocos retan su autoridad; y aun aquellos que se atreven son incapaces de hacer válido ese reto en contra de los órganos represivos del Estado.

El Kremlin también ha demostrado ser capaz de cumplir su propósito de erigir en Rusia, sin tomar en cuenta los intereses de sus habitantes, una empresa industrial de metalurgia pesada que a ciencia cierta aún no se ha terminado pero que sigue creciendo y empieza a competir con las de los otros grandes países industriales. Sin embargo, tanto el mantenimiento de la seguridad política interna como la construcción de la industria pesada, han sido realizados con un terrible costo de vidas, esperanza y energía humanas. Se han requerido trabajos forzados en una escala sin precedentes en la actualidad, en condiciones de paz. Ha conllevado la negligencia o el abuso sobre otras fases de la vida económica soviética, particularmente la agricultura, la producción de bienes de consumo, casa y transporte.

A todo esto, la guerra ha añadido su tremendo tributo de destrucción, muerte y exterminio humanos. Como consecuencia, tenemos actualmente en Rusia una población cansada física y espiritualmente. La masa del pueblo está desilusionada, escéptica y no tan predispuesta como antes a la atracción mágica que el poder soviético todavía irradia entre sus seguidores de fuera. La avidez con la cual la gente se acogió a la breve tregua concedida a la Iglesia por razones 
tácticas durante la guerra, fue un testimonio elocuente de que su capacidad de fe y devoción encontraba muy pobre expresión en los propósitos del régimen.

En estas circunstancias, la fuerza física y nerviosa del pueblo llega a un límite. Este límite es absoluto, y representa un obstáculo inclusive para las dictaduras más crueles, puesto que más allá de él no se puede arrastrar al pueblo. Los campos de trabajos forzados y otros mecanismos de coacción proveen medios temporales para obligar a la gente a trabajar más tiempo del que su voluntad o las presiones económicas les dictarían; pero quienes sobreviven a ellos envejecen prematuramente y deben ser considerados como víctimas humanas de las demandas de la dictadura. En cualquier caso, sus mejores capacidades han dejado de estar disponibles para la sociedad y no pueden ser enlistadas para dar servicio al Estado.

Aquí sólo puede ayudar la generación más joven. La generación más joven, pese a todas las vicisitudes y sufrimientos, es numerosa y vigorosa; y los rusos son personas con talento. Pero aún queda por ver cuáles serán los efectos que las tensiones anormales de la dictadura soviética - aumentadas enormemente durante la guerra - tendrán sobre el desarrollo maduro de la niñez. Con excepción de las más remotas granjas y aldeas, en la Unión Soviética prácticamente han dejado de existir cosas tales como la seguridad normal y la placidez del hogar. Y los observadores aún no están seguros de que esto no vaya a dejar huella en la capacidad global de la generación que ahora llega a la madurez.

Además, tenemos el hecho de que el desarrollo de la economía soviética, si bien puede enumerar algunos logros formidables, ha sido precario, irregular y disparejo. Los comunistas rusos que hablan del "desarrollo desigual del capitalismo" deberian ruborizarse al contemplar su propia economia nacional. Aquí ciertas ramas de la vida económica, como las industrias metalírgica y pesada, han sido impulsadas, fuera de toda proporción, dejando a un lado otros sectores de la economía. Aqui hay una nación que lucha por convertirse en un corto periodo en una de las naciones industriales del mundo, a pesar de carecer de una red de carreteras que merezca tal nombre y disponer sólo de una red de ferrocarriles relativamente primitiva. Mucho se ha hecho para aumentar la eficiencia del trabajo y para enseñar a los campesinos primitivos algo acerca del funcionamiento de las máquinas. Pero el mantenimiento es aún una deficiencia notoria de toda la economía soviética. La construcción es apresurada y de pobre calidad. La depreciación debe ser enorme. Y en los vastos sectores de la vida económica aún no ha sido posible introducir nada parecido a la cultura general de la producción y al autorrespeto, que caracterizan al trabajador calificado de Occidente.

Es difícil que estas deficiencias sean corregidas a corto plazo por una población cansada y sin ánimos, que ha trabajado largamente a la sombra del miedo y la obligación. Y mientras no sean superadas, Rusia permanecerá económicamente como una nación vulnerable $y$, en cierto sentido, impotente, capaz de exportar sus entusiasmos y radiar el extraño encanto de su primitiva vitalidad política, pero incapaz de respaldar esos artículos de exportación con evidencias reales de poder material y prosperidad.

Mientras tanto, una gran incertidumbre se cierne sobre la vida política de la Unión Soviética. Es la incertidumbre relacionada con la 
transferencia de poder de un individuo o grupo de individuos a otros.

Éste es, por supuesto, el notorio problema de la posición personal de Stalin. Debemos recordar que suceder en el pináculo a Lenin y obtener la preeminencia en el movimiento comunista, fue la única transferencia de autoridad individual que había experimentado la Unión Soviética. Llevó doce años consolidar esa transferencia! Costó la vida de millones de personas y sacudió al Estado hasta sus cimientos. Los concomitantes temblores se sintieron en todo el movimiento revolucionario internacional, para desventaja del propio Kremlin.

Siempre es posible que otra transferencia de poder preeminente tenga lugar callada y conspicuamente, sin repercusión alguna. Pero de nuevo, es posible que los aspectos involucrados originen, para usar las palabras de Lenin, una de esas "increíbles transiciones veloces" que llevan de una "sutil decepción" a la "salvaje violencia" que caracteriza a la historia rusa, y es capaz de sacudir hasta los cimientos del poder soviético.

Pero este asunto no concierne sólo al propio Stalin. Desde 1938, ha habido una peligrosa congelación de la vida política en los más altos círculos del poder soviético. El Pleno del Congreso de los Soviets, en teoría el órgano supremo del Partido, supuestamente debe reunirse por lo menos una vez cada tres años. Pronto se cumplirán ocho años desde su último encuentro. Durante este periodo los miembros del Partido se han duplicado. La mortandad en el Partido durante la guerra fue enorme; cerca de la mitad de sus miembros actuales ingresaron desde que tuvo lugar el último congreso del Partido. Mientras tanto, sigue en la cúspide el mismo pequeño grupo, pese a una sorprendente serie de vicisitudes nacionales. Seguramente existe alguna razón por la cual las experiencias de la guerra trajeron cambios politicos fundamentales a todos los grandes gobiernos de Occidente. Seguramente las razones de ese fenómeno son tan importantes como para estar presentes en algún lugar de la oscura vida política soviética. Y sin embargo, en Rusia no se las ha reconocido.

A raíz de esto debe suponerse que inclusive es una organización tan altamente disciplinada como la del Partido Comunista debe haber una creciente divergencia en edad, perspectiva e intereses entre la gran masa de sus miembros, que ingresaron recientemente al movimiento y la pequeña y autoperpetuante camarilla de hombres de la cúspide, con los cuales la mayoría de los miembros del Partido nunca se han reunido, con los cuales no han conversado, y con los cuales no pueden tener intimidad política.

¿Quién podría decir si, en estas circunstancias, el posible rejuvenecimiento de las altas esferas de la autoridad (que es sólo cuestión de tiempo) podrá desarrollarse suave y pacíficamente, o si los rivales en lucha por el poder más alto no echarán mano de esas masas políticamente inmaduras y sin experiencia a fin de encontrar apoyo a sus respectivas demandas? Si esto sucediera, habria extrañas consecuencias para el Partido Comunista: en general sus miembros han sido ejercitados sólo en las prácticas de disciplina de hierro y obediencia y no en las artes del acuerdo y la adaptación. Y si la desunión se apodera del Partido y lo paraliza, el caos y la debilidad de la sociedad rusa se revelarian en forma insólita. Porque, como hemos visto, el poder soviético es sólo una corteza que contiene una masa amorfa de seres humanos entre los cuales no se tolera ninguna estructura organizacional independiente. En Rusia ni siquiera hay algo parecido a un gobierno local. La presente generación de rusos no ha conocido la 
espontaneidad de la acción colectiva. En consecuencia, si ocurriera algo que interfiriera con la unidad y eficacia del Partido como instrumento político, la Rusia soviética podría cambiar de la noche a la mañana y después de haber sido una de las más poderosas, se convertiria en una de las sociedades más débiles y dignas de lástima.

Por lo tanto, el futuro del poder soviético no puede ser de manera alguna tan seguro como quiere hacerlo aparecer, frente a los hombres del Kremlin, la capacidad rusa para el autoengaño. Ellos han demostrado que pueden quedarse con el poder. Lo que aún está por verse es qué tan sigilosa y fácilmente entregarán el poder a otros. Mientras tanto, las dificultades de su gobierno y las vicisitudes de la vida internacional se llevan una buena parte de la fuerza y las esperanzas del gran pueblo en el cual descansa el poder. Es curioso notar que la fuerza ideológica de la autoridad soviética es ahora mayor en las áreas que traspasan las fronteras de Rusia, más allá de su control policiaco. Este fenómeno trae a la mente la comparación empleada por Thomas Mann en su gran novela Los Buddenbrooks. Al observar que las instituciones humanas con frecuencia muestran un brillo exterior en el momento en que el decaimiento interior está en realidad muy avanzado, comparaba a la familia Buddenbrook, en los días de mayor encanto, con aquellas estrellas cuya luz brilla más en este mundo cuando en realidad hace tiempo que han dejado de existir. ¿Y quién puede asegurar que la fuerte luz que irradia el Kremlin sobre las personas insatisfechas del mundo occidental no es el poderoso brillo posterior de una constelación que en la actualidad está menguando? Esto no puede ser probado. Y tampoco puede ser refutado. Pero subsiste la posibilidad (fuerte en opinión de este autor) de que el poder soviético, al igual que el mundo capitalista que ha concebido, lleva dentro de sí las semillas de su propia destrucción y que el brote de tales semillas está muy avanzado.

\section{IV}

Es claro que los Estados Unidos no pueden esperar, para un futuro cercano, disfrutar de intimidad política con el régimen soviético. Deben continuar viendo a la Unión Soviética como un rival, no como a un compañero, en la arena pólítica. Deben continuar con la certeza de que la política soviética no reflejará un amor abstracto por la paz y la estabilidad, ni una esperanza real en la posibilidad de una coexistencia feliz y permanente de los mundos socialista y capitalista, sino más bien una presión cautelosa y persistente encaminada hacia la ruptura y debilitamiento de toda influencia y poder rivales.

Esto lo contrapesa que Rusia, como oponente del mundo occidental en general, es todavía, con mucho, la parte más débil, que la política soviética es muy flexible, y que la sociedad soviética bien puede contener deficiencias que consiguientemente debilitarán su potencial total. Por sí mismo esto garantizaría a los Estados Unidos con plena confianza la entrada a una política de firme contención, planeada para confrontar a los rusos con contrafuerzas inalterables en cualquier punto que revele intromisión en los intereses de un mundo pacífico y estable.

Pero en la actualidad las probabilidades para la política norteamericana no están de ninguna manera limitadas a mantenerla firme y desear lo mejor. Es totalmente posible que los Estados Unidos influ- 
yan con sus acciones en el desarrollo internacional, tanto dentro de Rusia como en el movimiento comunista internacional, por el cual la política rusa está ampliamente determinada. Esto no se limita a las modestas medidas de actividad informativa que este gobierno puede desplegar en la Unión Soviética o en otras partes, aunque eso también es importante. Es más bien una cuestión del grado en el cual los Estados Unidos puedan crear entre la gente del mundo la impresión generalizada de ser un país que sabe lo que quiere, que resuelve con éxito los problemas de su vida interna y afronta las responsabilidades de una potencia mundial, y que tiene una vitalidad capaz de enfrentar los mayores problemas ideológicos de esta época. En la medida en que tal impresión pueda ser creada y mantenida, las metas del comunismo ruso parecerán estériles y quijotescas, las esperanzas y entusiasmos de los seguidores de Moscú menguarán, y se causarán más tensiones en la política extranjera del Kremlin. Porque la paralizada decrepitud del mundo capitalista es la llave de la filosofía comunista. Inclusive el que Estados Unidos no hubiese experimentado la pronta depresión económica que se ha predecido con voracidad en la Plaza Roja desde que cesaron las hostilidades, habría tenido profundas e importantes repercusiones en el mundo comunista.

Por la misma razón, las muestras de indecisión, desunión y desintegración interna dentro de este país tendrian un estimulante efecto en todo el movimiento comunista. Siempre que se hace evidente alguna de estas tendencias, un estremecimiento de esperanza y entusiasmo atraviesa el mundo comunista; un nuevo garbo puede notarse en el paso de Moscú; nuevos grupos de simpatizantes extranjeros suben a lo que ellos sólo pueden ver como el carro triunfal de la política internacional; y la presión rusa aumenta en los asuntos internacionales.

Sería exagerado decir que el comportamiento norteamericano, solo y sin apoyo, podría ejercer un poder de vida o muerte sobre el movimiento comunista y traer consigo la pronta caída del poder soviético en Rusia. Pero los Estados Unidos tienen la capacidad de aumentar enormemente las tensiones con las cuales debe operar la política soviética, para forzar al Kremlin a adoptar un mayor grado de modernización y circunspección que el que ha observado en años recientes, y de esta manera promover las tendencias que finalmente encontrarán la salida ya sea mediante la ruptura o la gradual distensión del poder soviético. Porque ningún movimiento místico o mesiánico -y sobre todo no el del Kremlin- puede encarar indefinidamente la frustración sin ajustarse a la lógica de tal estado de cosas.

Así, la decisión realmente recaerá en gran medida en este país. El tema de las relaciones soviético-norteamericanas es en esencia una prueba del valor global de los Estados Unidos como nación entre las naciones. Para evitar la destrucción los Estados Unidos sólo necesitan evaluar sus mejores tradiciones y mostrarse a si mismos dignos de la preservación de una nación tan grande. Seguramente, nunca habria una prueba más justa que ésta de la cualidad nacional. A la luz de las circunstancias, el observador cuidadoso de las relaciones ruso-norteamericanas no encontrará motivo de queja en el reto que lanza el Kremlin a la sociedad norteamericana. Más bien experimentará cierta gratitud hacia la providencia que, al proveer al pueblo norteamericano de este valor implacable, ha hecho que su seguridad total como nación dependa de que, unido, impulse y acepte las responsabilidades de liderazgo moral y político que la historia tan abiertamente les ha asignado. 